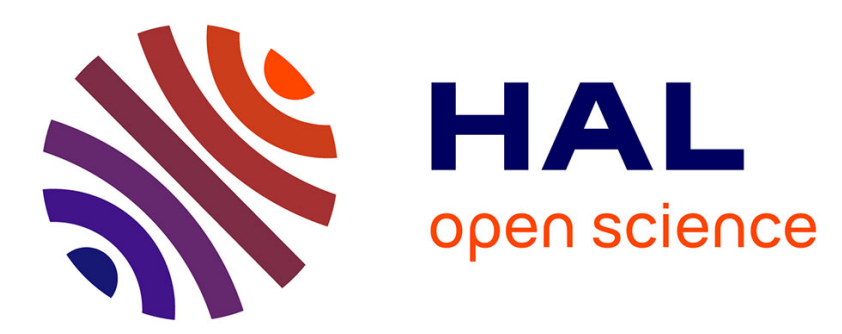

\title{
Innovative conductive polymer composite coating for aircrafts lightning strike protection
}

Vincent Bedel, Antoine Lonjon, Eric Dantras, Michel Bouquet

\section{To cite this version:}

Vincent Bedel, Antoine Lonjon, Eric Dantras, Michel Bouquet. Innovative conductive polymer composite coating for aircrafts lightning strike protection. Journal of Applied Polymer Science, 2019, 137, pp.1-11. 10.1002/app.48700 . hal-02364732

\section{HAL Id: hal-02364732 \\ https://hal.science/hal-02364732}

Submitted on 15 Nov 2019

HAL is a multi-disciplinary open access archive for the deposit and dissemination of scientific research documents, whether they are published or not. The documents may come from teaching and research institutions in France or abroad, or from public or private research centers.
L'archive ouverte pluridisciplinaire HAL, est destinée au dépôt et à la diffusion de documents scientifiques de niveau recherche, publiés ou non, émanant des établissements d'enseignement et de recherche français ou étrangers, des laboratoires publics ou privés. 


\section{Open Archive Toulouse Archive Ouverte (OATAO)}

OATAO is an open access repository that collects the work of Toulouse researchers and makes it freely available over the web where possible

This is an author's version published in: http://oatao.univ-toulouse.fr/25087

Official URL: https://doi.org/10.1002/app.48700

\section{To cite this version:}

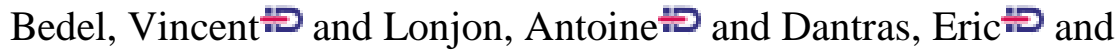
Bouquet, Michel Innovative conductive polymer composite coating for aircrafts lightning strike protection. (2019) Journal of Applied Polymer Science, 137. 1-11. ISSN 0021-8995

Any correspondence concerning this service should be sent to the repository administrator: tech-oatao@listes-diff.inp-toulouse.fr 


\title{
Innovative conductive polymer composite coating for aircrafts lightning strike protection
}

\author{
Vincent Bedel, ${ }^{1,2}$ Antoine Lonjon $\mathbb{D}^{1}{ }^{1}$ Éric Dantras, ${ }^{1}$ Michel Bouquet ${ }^{2}$ \\ ${ }^{1}$ CIRIMAT, Université de Toulouse, CNRS, Physique des Polymères, 118 route de Narbonne 31062, Toulouse cedex 09, France \\ ${ }^{2}$ Institut de Recherche Technologique (IRT) Saint Exupéry, 3 rue Tarfaya, CS 3443631405 Toulouse cedex 4, France \\ Correspondence to: A. Lonjon (E-mail: antoine.Ionjon@univ-tlse3.fr)
}

\begin{abstract}
A new kind of high electrical conductive epoxy coating with low filler rate was investigated for lightning strike protection (LSP) of carbon fiber reinforced polymer (CFRP). The coating without CFRP substrate was firstly studied. The influence of silver submicronic wires (AgSWs) with a high aspect ratio on the electrical behavior is observed; that is, the electrical resistivity evolution, the current density value, and the electrical conduction mechanisms as function of temperature. The preponderant electrical conduction mechanism is an Ohmic behavior. The higher level of conductivity obtained is $5.5 \times 10^{5} \mathrm{~S} \mathrm{~m}^{-1}$ for $9 \%$ vol of AgSWs. Lightning strike tests were carried out on an epoxy/AgSWs coating filled with $8 \%$ in volume $(74 \mathrm{gsm})$ and deposited on a CFRP. The ultrasonic testing after lightning strike on coated CFRP shows no structural delamination and demonstrates the interest of this new route for an efficient LSP. ๑ 2019 Wiley Periodicals, Inc. J. Appl. Polym. Sci. 2019, 137, 48700.
\end{abstract}

KEYWORDS: Applications; coatings; thermosets

DOI: $10.1002 / a p p .48700$

\section{INTRODUCTION}

Thermoset matrices reinforced by carbon fibers (CFRP) are used in aeronautic structural parts since the last decades, mainly for their lightweight. However, CFRP materials are complex and are characterized by an intrinsic structural anisotropy. This heterogeneous structure implies various types of electrical conductivity levels with the worst value along the transversal ax. ${ }^{1,2}$ The electrical conductivity improvement of CFRP remains a challenging task. The high current density observed during lightning strike implies various types of damages, ${ }^{3-5}$ for example, critical degradations of the mechanical properties by delamination (labeled direct effect ${ }^{3,6}$ ). The aeronautical industry has explored different kinds of solutions to preserve the integrity of the composite structure ${ }^{7,8}$ from lightning current. Currently, the lightning strike protection (LSP) is based on surface metallic inserts to reduce the damages. ${ }^{7,9}$ These protections could be metallic foil, perforated metallic foil, metallic mesh, or expanded metal foil bonded on the composite structure surface. The design and the morphology of the LSP depend on the protected area. However, this kind of LSP induces a significant overweight associated with an increase of the complexity in composite process. ${ }^{8,10}$ The weak value of CFRP electrical conductivity is due to the dielectric behavior of the polymer matrix. An increase of this electrical conductivity could be an alternative strategy to reduce the damage induced by lightning current. To overcome these drawbacks, the first work described the introduction of carbon fillers. The literature is meanly focused on carbon fillers dispersion such as carbon black, ${ }^{11,12}$ carbon nanotubes, ${ }^{13-15}$ carbon nanofibers, ${ }^{16}$ or graphene. ${ }^{17,18}$ The conductive behavior is obtained above the percolation threshold which depends on the particles aspect ratio. This phenomenon was described by Balberg et al. ${ }^{19}$ and Kirkpatrick. ${ }^{20}$ The lowest values of filler content were obtained with CNTs close to $0.05 \% \mathrm{vol}^{21}$ However, the conductivity level above the percolation threshold capped at $10^{-1} \mathrm{~S} \mathrm{~m}^{-1}$. Better values of electrical conductivity are reported with metallic fillers ${ }^{22-29}$ near $10^{3} \mathrm{~S} \mathrm{~m}^{-1}$ but for a filler content upper than $20 \%$ vol. This ratio decreases drastically the mechanical properties and overweights the composite. An increase of the metallic fillers aspect ratio allows us to decrease the filler content. ${ }^{30}$ In this case, the percolation threshold is reached for a volume fraction lower than $1 \% \mathrm{vol}^{24,31}$ keeping the mechanical properties ${ }^{32,33}$ and the lightweight of the polymer composites. Best results in epoxy matrix were obtained with silver nanowires $^{31}$ which exhibit an electrical conductivity around $10^{2} \mathrm{~S} \mathrm{~m}^{-1}$ for particles content lower than $5 \% \mathrm{vol}$.

This work examines the electrical behavior of a conductive composite coating epoxy/silver submicronic wires (AgSWs) for LSP. The current density as a function of the electric field characteristics was studied for different AgSWs volume fraction. The aim was to develop an epoxy coating with the highest electrical 
conductivity for a filler content lower than $10 \%$ vol. The currentvoltage curves were studied as a function of temperatures. The limit current density was carried out for various filler contents. Finally, a normalized lightning strike test on CFRP was performed for the best conductive coating. A comparison with the classical ECF protection was performed.

\section{MATERIALS AND METHODS}

\section{Epoxy Matrix Coating}

The epoxy matrix used in this study is a mixture of MBDA $\left[4,4^{\prime}-\right.$ methylenebis( $N, N$-diglycidylaniline)], DGEBA (bisphenol A diglycidyl ether), and DGEBF (bisphenol-F diglycidyl ether). The amine hardener is composed by a DETDA (diethyltoluenediamine) and a DACH (1,2 diaminocyclohexane) supplied by Sicomin for RTM structural applications.

\section{Silver Submicronic Wires}

AgSWs are elaborated with a modified polyol process ${ }^{34}$ inspired by Sun and Wiley works. ${ }^{35-37}$ It consists in the reduction of $\mathrm{AgNO}_{3}$ with ethylene glycol solution. A unidirectional controlled silver crystal growth is promoted. The crystal growth is assisted by polyvinylpyrrolidone which is preferentially adsorbed on $\{100\}$ crystal faces. AgSWs are washed and stored in ethanol. The mean diameter is around $200 \mathrm{~nm}$ and $40 \mu \mathrm{m}$ for the mean length; that is, an aspect ratio close to $220 .{ }^{34}$ This polyol process allows to produce up to $100 \mathrm{~g}$ of AgSWs.

\section{Coating Processing}

Composite coatings were elaborated by mixing an ethanol suspension of AgSWs in the epoxy part. Then, hardener was poured (stoichiometric ratio 75/25 in mass). The final suspension with epoxy resin and AgSWs was obtained by mechanical and ultrasonic stirring. The coating was deposited through a paint spray gun at room temperature after the ultrasonic treatment. A glass sheet of $20 \times 18 \times 1.1 \mathrm{~mm}$ was used as substrate for the currentvoltage experiment. A dumbbell shape sample was used (Figure 1) to drive the electron flow through a known dimension section. Samples have approximately the same channel dimensions; the current value was normalized to the section. A specific attention was paid to decrease the contact resistances between the sample and the wires of the experimental measurement setup with a colloidal silver liquid.

For the lightning strike tests, the substrate was replaced by CFRP with a lay-up representative of a structural composite: that is, $[(0 / 45 / 90 /-45) s] s$ and $500 \times 500 \times 3 \mathrm{~mm}$. After spraying, all the coating samples were cured with different steps from 40 to $200{ }^{\circ} \mathrm{C}$. The coating thickness was between 40 and $100 \mu \mathrm{m}$. AgSWs content was checked by thermogravimetric analysis from room temperature to $1000{ }^{\circ} \mathrm{C}$ at a heating rate of $20^{\circ} \mathrm{C} \mathrm{min} \mathrm{m}^{-1}$ under synthetic air atmosphere.

\section{Expanded Copper Foil Lightning Strike Protection}

The LSP coating elaborated in this work is compared to the Expanded Copper Foil73 (ECF73) ${ }^{7}$ used for aircraft. The ECF73 is composed of a prepreg epoxy adhesive with a chopped strand mat of glass fiber and an ECF giving a surface density about $73 \mathrm{gsm}$ (grams by square meter). The global surface density of this LSP is around $170 \mathrm{gsm}$ and is applied on the top of the CFRP with usual vacuum bag processing assisted by temperature ramp up to $180^{\circ} \mathrm{C}$.

\section{Scanning Electron Microscopy}

The dispersion of the AgSWs in the coating was observed by electronic microscopy with a JEOL JSM 6700F instrument (scanning electron microscope, SEM) under a voltage between 10 and $19 \mathrm{keV}$. Backscattered electron and secondary electron detection modes were used to increase the contrast between AgSWs and epoxy matrix and to observe the morphology and the repartition of the fillers into the matrix respectively. The coating edge cut was obtained at room temperature.

\section{Current-Voltage Measurement and Mechanisms}

Current-voltage characteristics of conductive coatings were obtained with a Keithley SourceMeter 2420 plugged to the sample in four wires mode controlled by a LabVIEW program. The sample was held by two crocodile clips inside a cryostat under helium atmosphere. An Eurotherm 2408 allowed us to set the temperature. The measurement parameters like the minimum and maximum values of current or tension, the sampling rate (around

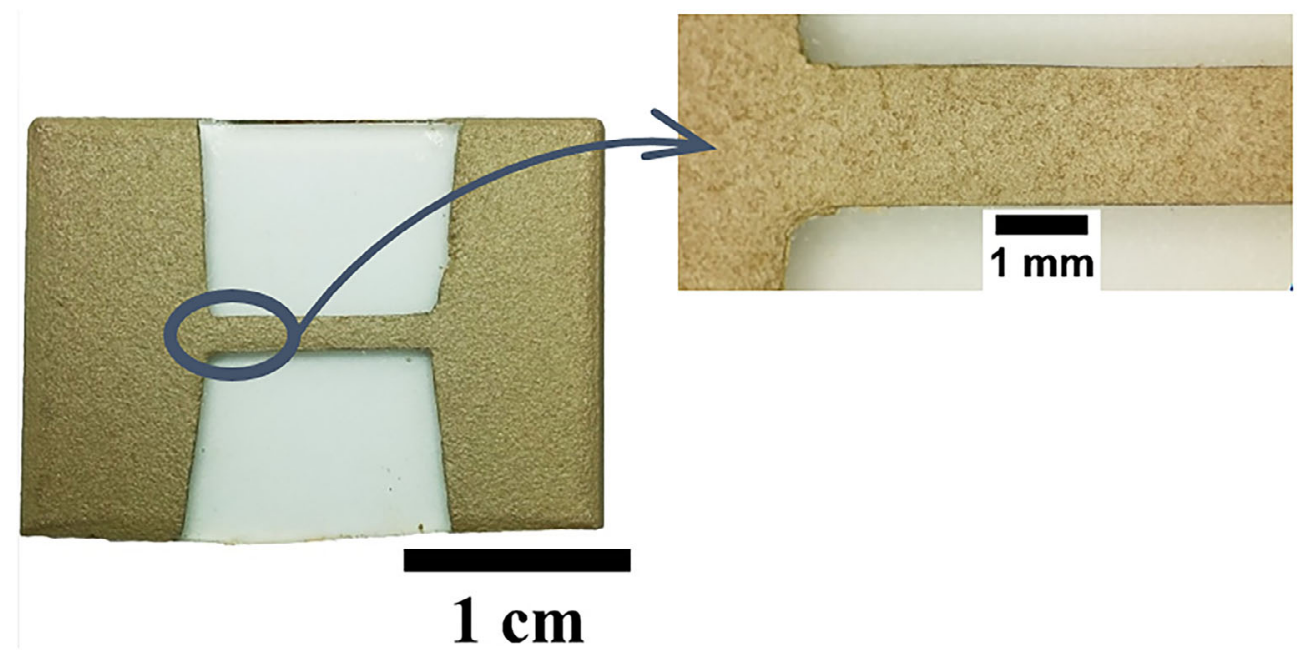

Figure 1. The dumbbell shape sample. [Color figure can be viewed at wileyonlinelibrary.com] 
25 points per $100 \mathrm{mV}$ ), the duration of the electric charge application ( $2 \mathrm{~s}$ for each point), sample dimensions, and temperature are implemented in the LabVIEW program. This system allows us to plot the $\mathrm{I}-\mathrm{V}$ curves to determine the dynamic resistivity and the dynamic current density, $\mathrm{J}\left(\mathrm{A} \mathrm{m}^{-2}\right)$. I-V curves of polymer composites filled with carbon ${ }^{38,39}$ were used to describe the conduction mechanisms. The charge carrier's mobility and the conductivity exhibit different behaviors corresponding to the chemical nature of the studied materials. In the case of heterogeneous materials like polymers and polymer composites, the chemical structure implies localized states inducing a "pseudocontinuum" in the band gap. The conductivity of these heterogeneous materials was governed by carriers mobility and was described by two mainly models. The band gap has a decreasing concentration of localized states between the valence band and the Fermi level, it is renamed "mobility gap." 40 The border between delocalized states and localized one is named mobility edge. Mott ${ }^{41}$ or Efros ${ }^{42}$ and Shklovskii describe the charge carriers mobility through the variable range hopping (VRH) model. ${ }^{41}$ This behavior can be also explained by another mechanism: the multiple trapping and release (MTR $)^{43,44}$ model. Both are driven by the temperature. For the VHR, the electronic activation between localized states come from two mechanisms, ${ }^{45}$ tunneling effect and hopping thermally assisted. The second is predominant at high temperatures. A study ${ }^{46}$ mentioned that VHR and MTR models are present in heterogeneous materials; but their prevalence is driven by the temperature. To sum up, at lowest temperature, the VHR model drives the conductivity by tunneling effect. For the intermediate temperatures, hopping is dominant. As the temperature increases, the conductivity mechanism switches to MTR. The I-V characteristics of such systems, conductor, semiconductor, or conductive composite have two meanly behaviour ${ }^{47}$ :

- a linear behavior, which traduces an Ohmic conductivity.

- a nonlinear behavior.

- $I=\frac{V}{x}$ (with $x>1$ ) which is the characteristic of a tungsten filament for example.

- $I=V^{x}$ (with $x>1$ ) which is the characteristic of space charges phenomenon. $^{48,49}$

The slope of the curve $\ln (J)=\ln (E)$ allows us to determine the conduction mechanism: that is, slope is equal to 1 for an Ohmic mechanism, and greater than 2 if charge carriers are injected in the sample. ${ }^{50}$

\section{Lightning Strike Test}

The aim is to observe the effect of the lightning strike current on the sample morphology and to evaluate the efficiency of the LSP by ultrasonic characterization. The test conditions were defined by the requirements of the standard ARP5412: Aircraft Lightning Environment and Related Test Waveforms. The conductive epoxy coating was compared to the ECF7 ${ }^{7}$ and we have focused our interest on area with a moderate risk of lightning impact (a specific zone labeled 2A).

The waveform of the lightning strike is defined for a zone (aeronautical structures are identified in different areas by a mapping as a function of the probability and the power of the lightning strike) and could be described by eq. (1) and Table I.

$$
i(t)=I_{0}\left(e^{-\alpha t}-e^{-\beta t}\right)
$$

where $I_{0}$ is the highest value of the current (A), $\alpha$ is the inverse of the impulsion time in $\mathrm{s}^{-1}$, and $\beta$ is the inverse of the ascent time in $s^{-1}$.

The amount of energy dissipated during the test was described by the square integration of eq. (1). This value permits to quantify the damages on the impacted zone. This specific energy (or action integral) is the square of the intensity multiplied by the impact duration.

The lightning strike tests were carried out at GERAC Electromagnetism Company. The CFRP sample was screwed between an aluminum frame and the support frame linked to the ground. The lightning current was applied with a jet diverter placed at $5 \mathrm{~cm}$ from the sample surface. The measurements were realized with a temperature between 15 and $35^{\circ} \mathrm{C}$, relative humidity lower than $85 \%$, and an atmospheric pressure ranging from 84 to $107 \mathrm{kPa}$.

\section{Ultrasonic Testing}

After the lightning strike test, the sample was inspected by C-scan mode ultrasonic testing. Only longitudinal waves were used to detect damages inside the volume. The transductor is installed on a motorized arm to scan the surface sample ( $x, y$ coordinates). It allows us to obtain the defaults distribution and their depth. The ultrasonic wave frequency was $5 \mathrm{Mhz}$, they were generated by 32 transductors. This frequency allows us to detect size default up to $500 \mu \mathrm{m}$.

\section{RESULTS AND DISCUSSION}

\section{Submicronic Wires Dispersion in the Matrix}

The AgSWs dispersion in the epoxy coating was observed by SEM. The coating surface [Figure 2(a)] and the edge [Figure 2 (b)] observations show a homogenous dispersion without large bundles. A slight orientation of the wires due to the elaboration process was observed. The AgSWs aspect ratio was preserved after the spraying process. The nanocomposite coating thickness was measured close to $50 \mu \mathrm{m}$.

Table I. Waveforms parameters

\begin{tabular}{llllll}
\hline Waveform & $l_{0}(\mathrm{~A})$ & $\alpha\left(\mathrm{s}^{-1}\right)$ & $\beta\left(\mathrm{s}^{-1}\right)$ & Action integral $\left(\mathrm{A}^{2} \mathrm{~s}\right)$ & Duration $(\mathrm{ms})$ \\
\hline A & 218810 & 11354 & 647265 & $2.0 \times 10^{6}$ & 5 \\
B & 11300 & 700 & 2000 & $2.9 \times 10^{4}$ & 25 \\
C & 400 & N/A & N/A & N/A & 5.5 \\
D & 109405 & 22708 & 1294530 & $2.5 \times 10^{5}$ & \\
\hline
\end{tabular}



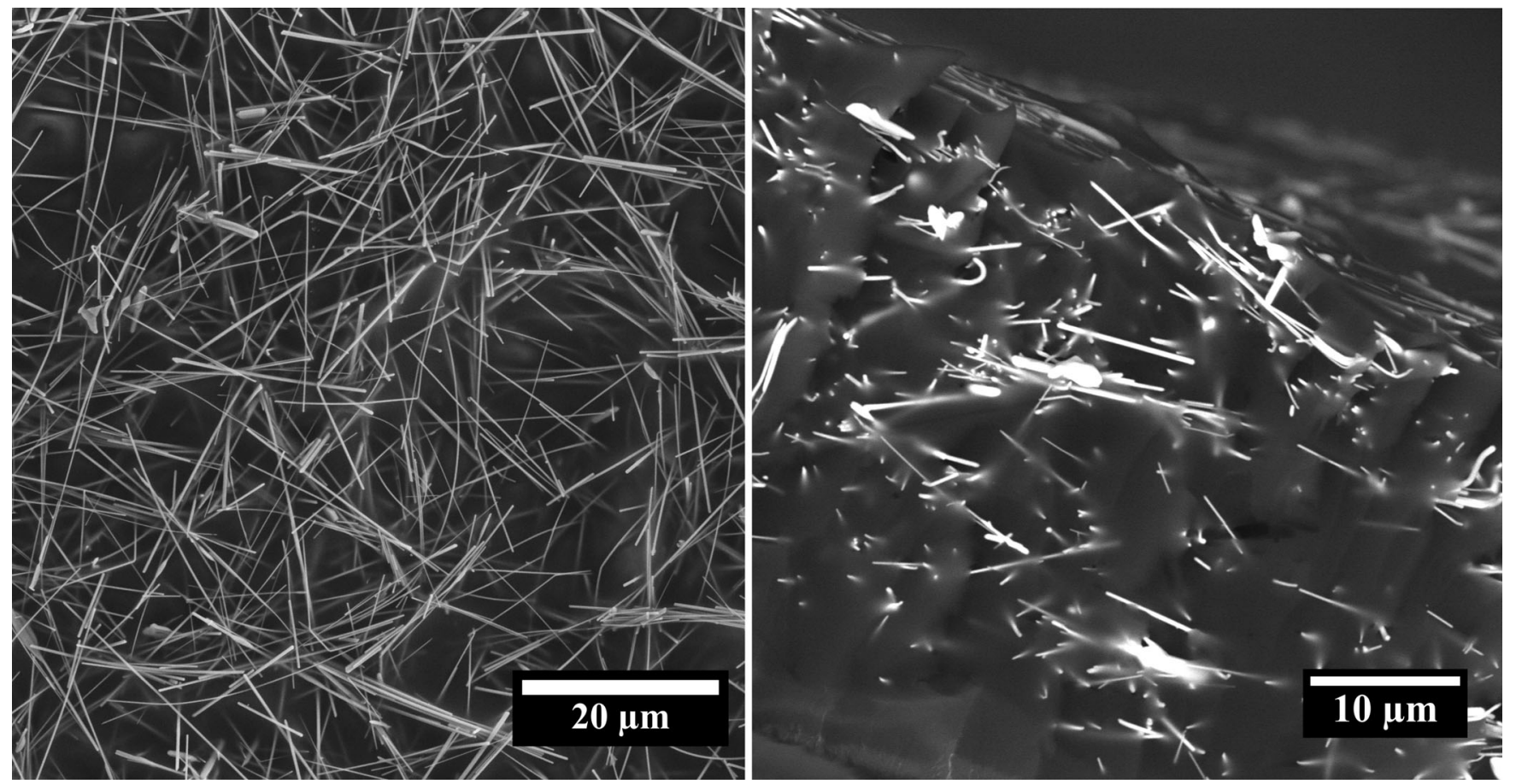

Figure 2. Poly(epoxy)/Ag 2\%vol AgSWs SEM images: (a) surface and (b) edge cut.

\section{Electrical Behavior}

Influence of AgSWs Content. Figure 3 shows the evolution of the current density as a function of the electric field for several filler contents above the percolation threshold. These measurements were carried out for low levels of electric field. A linear behavior is pointed out. The resistivity decreases with the filler content due to the increase of the conductive paths. The linear regression $\ln (J)=\ln (E)$ allows us to obtain a slope value close to 1 , corresponding to an

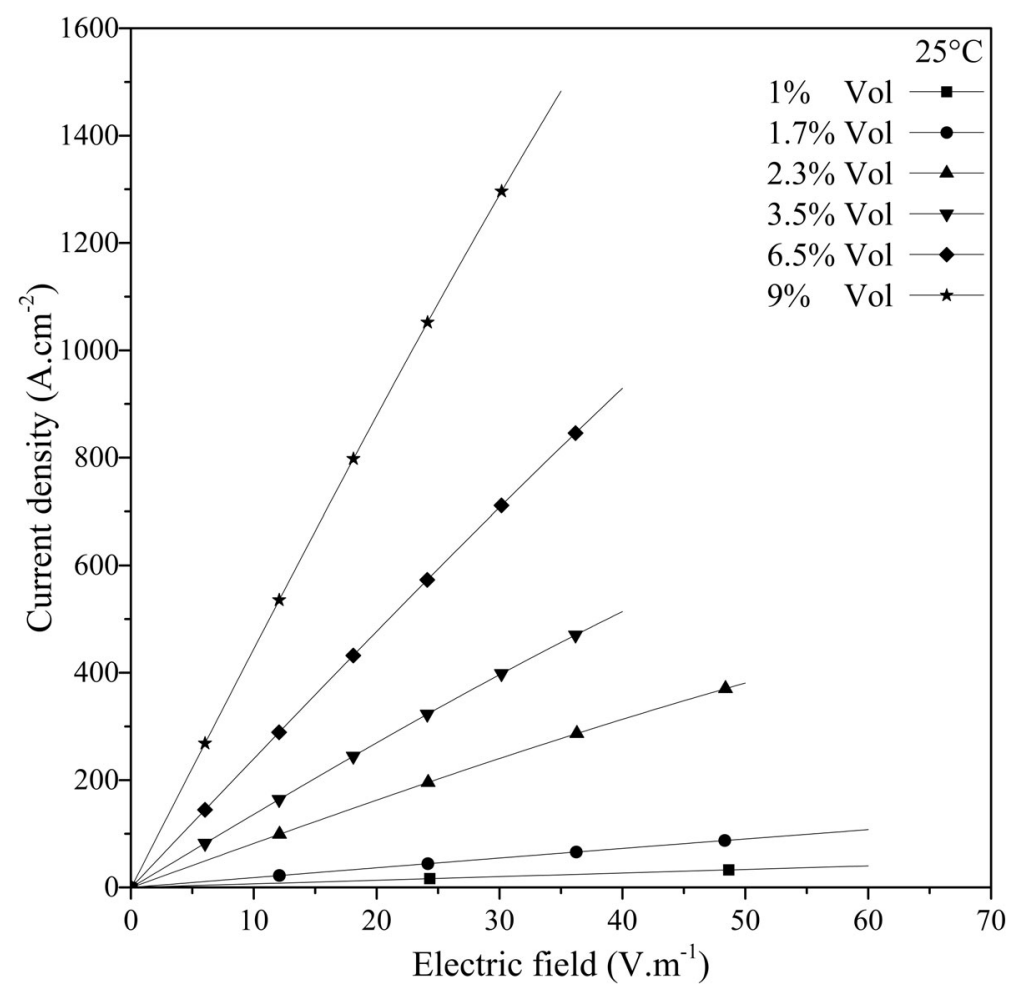

Figure 3. Current density as a function of electrical field for various AgSWs ratio in epoxy coating. 


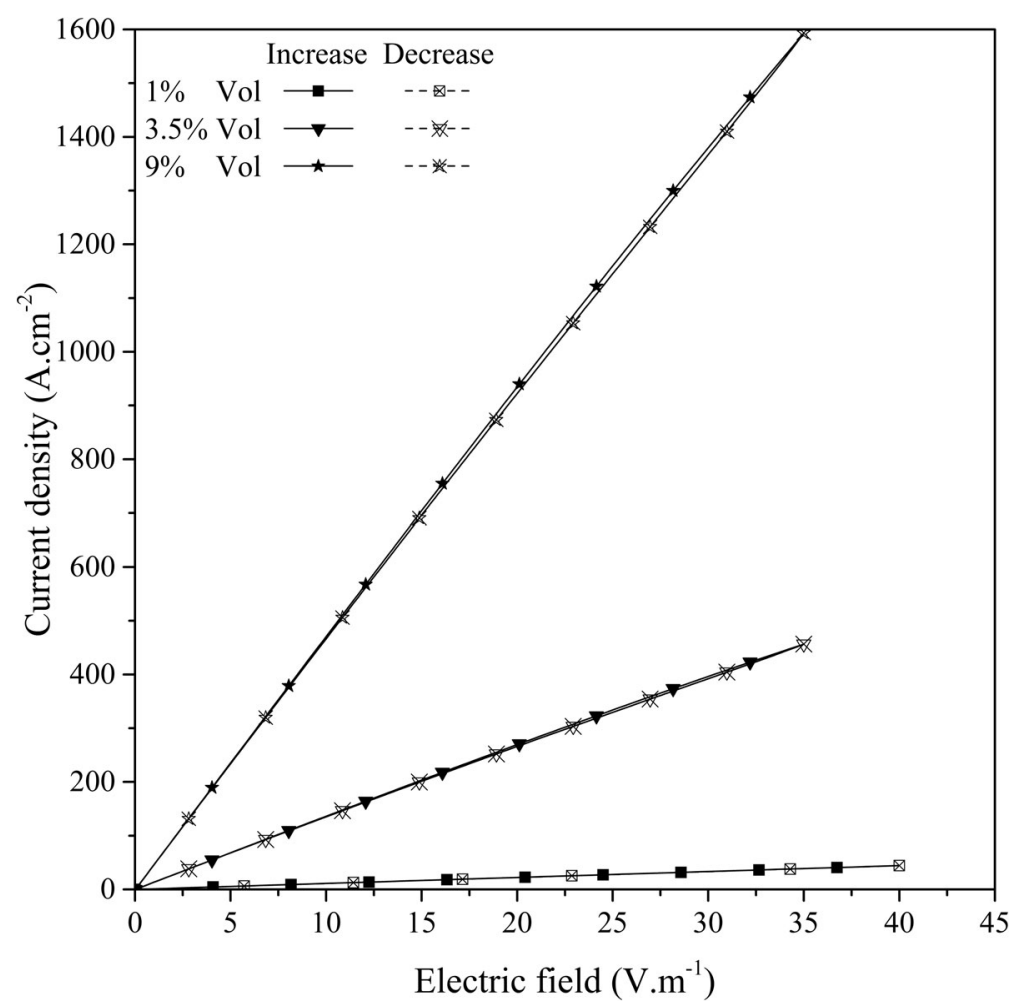

Figure 4. Current density as a function of electric field for successive increase and decrease electric field values at $25^{\circ} \mathrm{C}$.

Ohmic conductivity. The evolution of the average value of the resistance is not linear with silver wires content. For example, the current density of the $9 \%$ vol sample is not nine time higher than the $1 \%$ vol sample. The resistance of the $1 \% \mathrm{vol}$ is 60 times more important.

Test Reversibility. Successive increase and decrease electrical field scans were performed. Figure 4 reports results for three filler contents. For purpose of clarity, only three filler ratios were presented but a similar behavior was observed for all AgSWs content. For this electrical field range, the ascent and descent behavior are similar. The current injections through the sample for moderate current values have not modified the physical or chemical structure of the samples. The conductive mechanism looks to be the same.

Conductivity Behavior as a Function of Temperature. Figure 5 reports the influence of temperature on conductivity for the following isotherms: $-60,25,110$, and $150{ }^{\circ} \mathrm{C}$. For purpose of clarity, only three filler ratios were presented; a similar behavior was observed for all AgSWs content. A linear behavior was pointed out for the various isotherms. The conductivity associated with the slope was influenced by the temperature increase. Its evolution with the temperature is comparable to an Ohmic mechanism in metallic materials. This last mechanism seems to be preponderant, contrary to hopping one classically observed for conductive composites-based polymer. ${ }^{27,51,52}$

Conductivity evolution as function of temperature is described by the following phenomenological law deduced from the Ohm's law ${ }^{53-55}$ :

$$
\sigma(T)=\frac{1}{\rho_{0}\left[1+\alpha\left(T-T_{0}\right)\right]}
$$

with $\sigma(T)$ is the electrical conductivity in $\mathrm{S} \mathrm{m}^{-1}, \rho_{0}$ is the electrical resistivity at the temperature $T_{0}$ in $\Omega \mathrm{m}$, and $\alpha$ is the thermal coefficient in $K^{-1}$.

Data extracted from Figure 5 are used to determine the evolution of the conductivity as function of temperature. $\mathrm{J}(\mathrm{E})$ slope is reported in Figure 6 and fitted with eq. (2). The experimental values are well fitted by the model for all filler ratios. Thermal coefficient values deduced are reported in Table II and are independent from the filler content. $\alpha$ values for composites are close to the silver value; the discrepancy with the metal value is probably due to the contact resistances between each AgSWs in the conductive composite coating. This point confirms the similar composites behavior regarded to the metallic one.

For $9 \%$ vol of AgSWs, Figure 7 reports a conductivity value of $5.5 \times 10^{5} \mathrm{~S} \mathrm{~m}^{-1}$. As far as we know, it is the highest conductivity value reported in the literature for a composite polymer coating with low filler content. The well-known channel section and the volume filler ratio allow us to calculate the apparent diameter of an equivalent single wire (sAgW). The evolution does not follow a mixing law. The values calculated below are obtained at $25{ }^{\circ} \mathrm{C}$ :

$9 \times 10^{5} \pm 3 \times 10^{5} \mathrm{~S} \mathrm{~m}^{-1} 1 \%$ vol of Ag SWs.

$2 \times 10^{6} \pm 0.8 \times 10^{5} \mathrm{~S} \mathrm{~m}^{-1}$ for the sampled filled by $4.3 \% \mathrm{vol}$ of Ag SWs.

$7 \times 10^{6} \pm 1 \times 10^{6} \mathrm{~S} \mathrm{~m}^{-1}$ for the sampled filled by $9 \% \mathrm{vol}$ of Ag SWs.

To compare, the silver bulk conductivity was $6.2 \times 10^{7} \mathrm{~S} \mathrm{~m}^{-1}$ at $25{ }^{\circ} \mathrm{C}$ in the same range of electric field. It is interesting to 


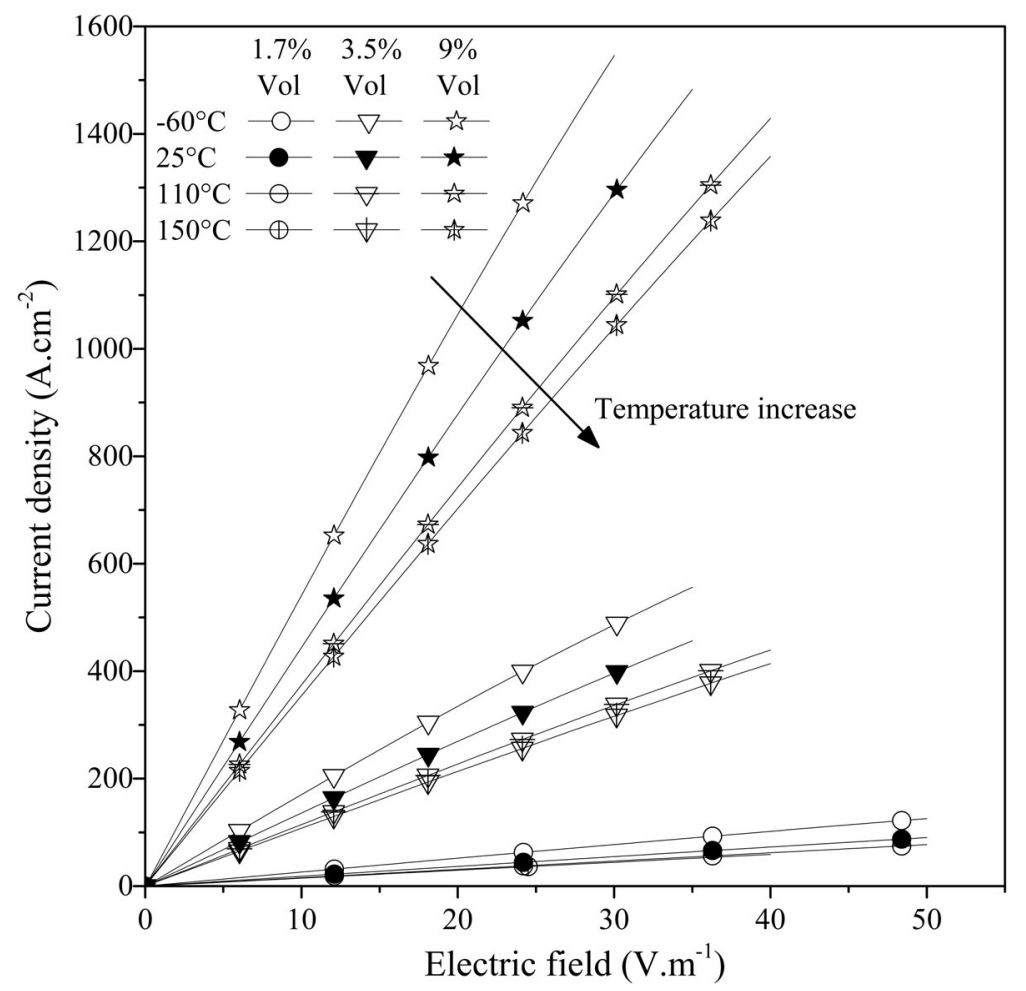

Figure 5. Current density as a function of electric field for different temperatures and filler ratios.

observe that the conductivity of this equivalent single silver wire becomes quickly close to the silver bulk conductivity when the filler ratio reaches $100 \%$ vol. This discrepancy (from 1 to $9 \% \mathrm{vol}$ ) could be attributed to the amount of "died arms" (pathways do not participate to the conduction) around the percolating clusters which decreases and the bonds between them increase.

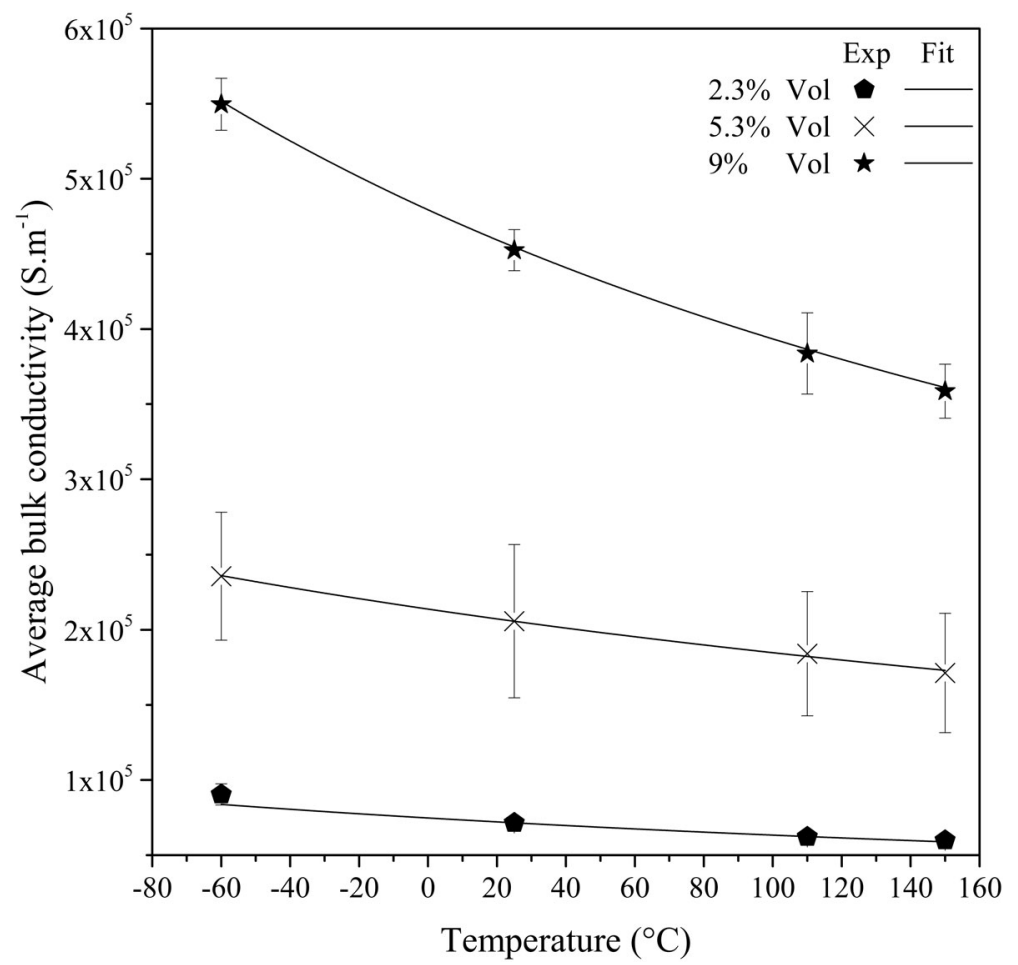

Figure 6. Average bulk conductivity (experimental data and fit) as a function of temperature and AgSWs ratio. 
Table II. Thermal coefficient values $\alpha$ as a function of filler ratio of AgSWs

\begin{tabular}{ll}
\hline Filler ratio (\% in volume) & $\alpha\left(\mathrm{K}^{-1}\right)$ \\
\hline 2.3 & $2.6 \times 10^{-3} \pm 0.1 \times 10^{-3}$ \\
5.3 & $1.51 \times 10^{-3} \pm 0.05 \times 10^{-3}$ \\
9 & $2.07 \times 10^{-3} \pm 0.04 \times 10^{-3}$ \\
100 (bulk) & $3.42 \times 10^{-3} \pm 1 \times 10^{-5} \mathrm{~K}^{-1}$ \\
\hline
\end{tabular}

Limit Electric Field. The conductive composite coatings were evaluated by measuring the maximum current density load for each sample at $25{ }^{\circ} \mathrm{C}$. Figure 7 shows the evolution of the current density as a function of the electrical field up to the breakdown.

In the vicinity of the breakdown, the current density value reaches a maximum (value reported in the inset of Figure 7) described by a plateau. After the breakdown, calcined areas are observed in the channel. This area is larger when the filler ratio decreases. The sample was definitively degraded by the sudden temperature increase. This behavior is probably associated with the melting of AgSWs. In order to confirm this assumption, we calculate the current value necessary to melt an equivalent bulk metallic wire, ${ }^{56,57}$ thanks to the following equation:

$$
C_{p} \cdot \rho_{v} \cdot l . S . \Delta T=I^{2} \cdot \rho_{0}\left[1+\alpha\left(T-T_{0}\right)\right] \frac{l}{S} \Delta t
$$

$$
I=\sqrt{\frac{C_{p} \cdot \rho_{v} \cdot S^{2} \cdot \Delta T}{\rho_{0}\left[1+\alpha\left(T-T_{0}\right)\right] \Delta t}}=\sqrt{\frac{C_{p} \cdot \rho_{v} \cdot S^{2} \cdot \Delta T}{\rho(T) \Delta t}}
$$

where $I$ is the current in $\mathrm{A}, C_{p}$ is the specific heat capacity in $\mathrm{J}$ $\mathrm{K}^{-1} \mathrm{~kg}^{-1}, \rho_{v}$ is the sample density in $\mathrm{kg} \mathrm{m}^{-3}, \Delta T$ is the temperature variation between the ambient temperature and the melting point of the sample, $l$ is the wire length in $\mathrm{m}, S$ is the wire section in $\mathrm{m}^{2}, \rho_{0}$ is the electrical resistivity at the temperature $T_{0}$ in $\Omega \mathrm{m}, \alpha$ is the thermal coefficient in $K^{-1}$, and $\Delta t$ is the current application time.

The well-known channel section and the volume filler ratio allow us to calculate the apparent diameter of an equivalent single wire $(\mathrm{sAgW})$. The current value calculated, thanks to eq. (3), and normalized by the sAgW section allows us to determine the theoretical current density level at the melting point for each electrical resistivity values (Table III and Figure 8).

We observe a discrepancy between the theoretical and experimental values with the increase of AgSWs content. In order to compare, the same calculation is done for a bulk silver wire; a

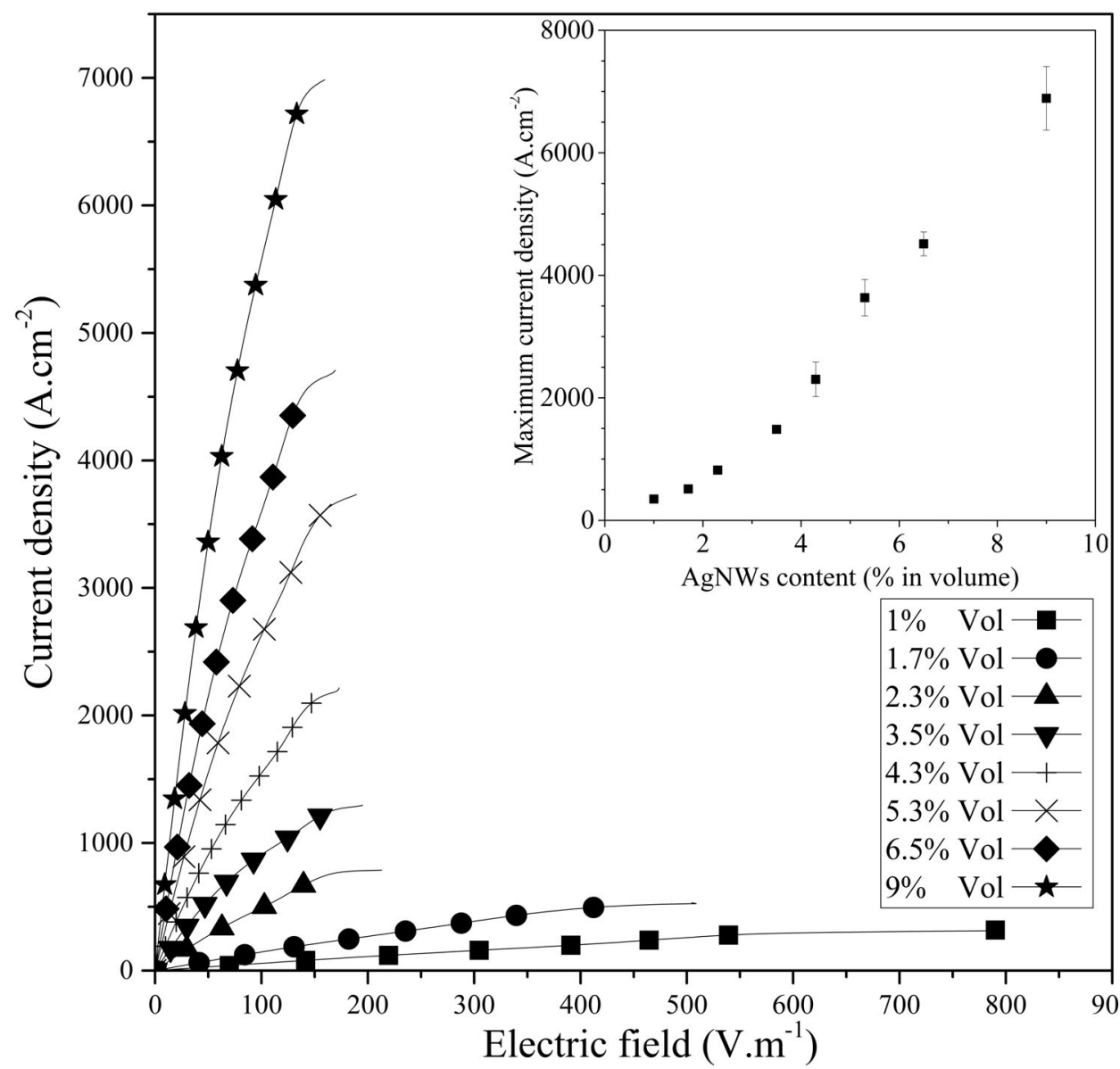

Figure 7. Current density as a function of electric field for several AgSWs ratios at $25^{\circ} \mathrm{C}$. Inset: maximum current density values as a function of the AgSWs volume content measured at the plateau of $J=f(U)$. 
current density of $13055 \mathrm{~A} \mathrm{~cm}^{-2}$ is necessary to melt. The higher values (more than $166 \%$ for a filler ratio of $1 \%$ vol, for example) obtained with conductive composites is explained by the modeling; eq. (3) is dedicated to homogeneous bulk metal. The geometrical aspect of the metallic conductor plays a key role in the mitigation of the current. In our case, the current circulates in a multitude of conductive paths created by the nanowires dispersed in a dielectric matrix. The electrical conductivity of the heterogeneous conductive materials is driven by different kinds of mechanism like Ohmic behavior or hopping. Above the percolation threshold, the conduction across percolation pathway is possible through an AgSWs infinite cluster. The conduction between wires implies an energy consumption proportional to wires number. ${ }^{9}$

$$
\int_{t_{0}}^{t} i^{2} d t_{(\text {per wire })}=\frac{\int_{t_{0}}^{t} i^{2} d t_{(\text {global })}}{N 2}
$$

where $i$ is the electrical current, $t_{0}$ and $t$ are durations of the current application, and $N$ is the number of wires.

The metallic wires act as an electric parallel circuit; that is, the current is divided by wires number. Equation (4) could be used to calculate the energy seen by each wire to conduct the total lightning strike energy across the conductive composite coating. Furthermore, the calcination area of the poly(epoxy) implies also an increase of the energy consumption in addition with the heat flow transfer to the glass substrate. From some samples, some failures in the glass substrate due to the fast temperature increase have been observed. These three points contribute to the discrepancy between the theoretical and the experimental values of the current density needed to melt an equivalent single silver wire (sAgW).

\section{Lightning Strike Results}

Electrical Waveform. The lightning strike simulation was carried out with the test conditions given in Table I. The current injection in the sample was leaded by the waveform B and then D. Thanks to the action integral calculation and the sample electrical resistance measurement, we can determine the energy amount dissipated by the LSP.

Visual Inspections. The visual inspection is the first level of the analysis after lightning strike test. These observations permit to

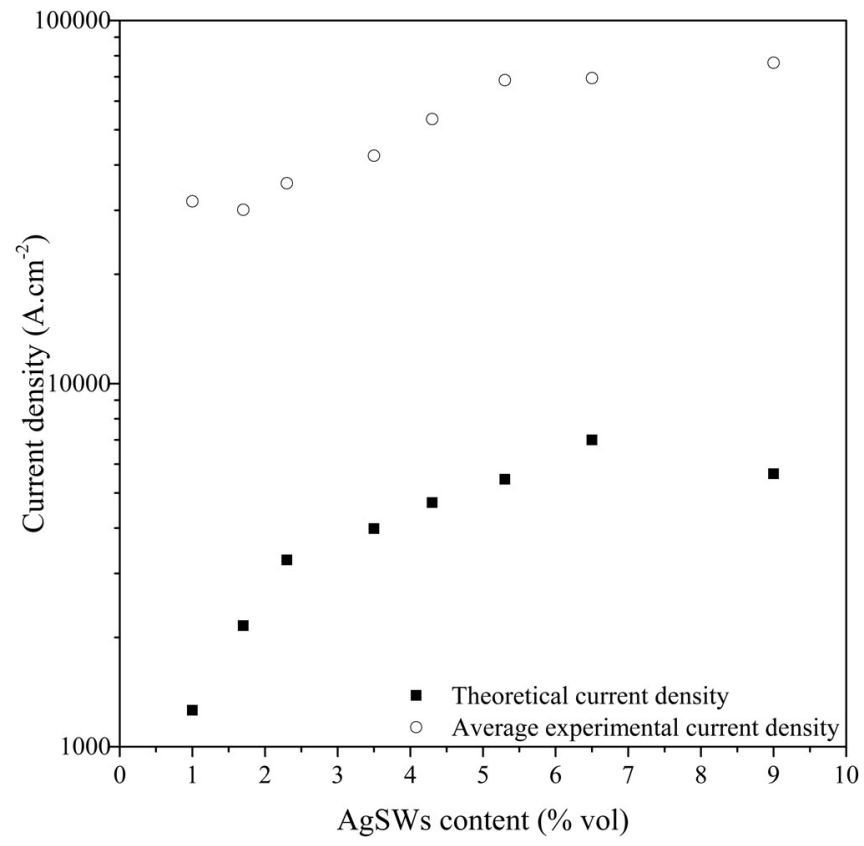

Figure 8. Current density as a function of AgSWs content for experimental and theoretical results.

determine the area concerned by the lightning current effect. This test does not give information on the mechanical integrity. The different configurations impacted by lightning strike before and after the test are shown in Figure 9. As expected, the unprotected CFRP exhibits a large and depth delaminated area with carbon fibers raise up to the sample edge. This damage corresponds to the carbon fibers impacted on the first layer of the unidirectional ply. The CFRP protected with LSP ECF73 showed a burned surface area with some sublimated copper conductive pathways but no raised fiber. The CFRP covered with $40 \mu \mathrm{m}$ in thickness $(\approx 74 \mathrm{gsm})$ of the conductive composite polymer coating filled with $8 \% \mathrm{vol}$ of AgSWs exhibits an area concerned close to the CFRP-ECF configuration. In the case of AgSWs conductive paint, we note a slight larger area due to the conductive surface coating burn. The CRFP structure looks to be protected in its depth.

Table III. Theoretical and experimental current density values of the melting point for several filler ratios

\begin{tabular}{lllll}
\hline $\begin{array}{l}\text { Filler } \\
\text { ratio (\%) }\end{array}$ & $\begin{array}{l}\text { sAgW } \\
\text { section }\left(\mathrm{m}^{2}\right)\end{array}$ & $\begin{array}{l}\text { Electrical } \\
\text { resistance }(\Omega)\end{array}$ & $\begin{array}{l}\text { Theoretical current } \\
\text { density for a sAgW }\left(\mathrm{A} \mathrm{cm}^{-2}\right)\end{array}$ & $\begin{array}{l}\text { Average experimental } \\
\text { current density for a sAgW }\left(\mathrm{A} \mathrm{cm}{ }^{-2}\right)\end{array}$ \\
\hline 1 & $1.33 \times 10^{-9}$ & 14.00 & 1261 & 34730 \\
1.7 & $1.71 \times 10^{-9}$ & 5.60 & 2155 & 30129 \\
2.3 & $4.45 \times 10^{-9}$ & 0.70 & 3269 & 35652 \\
3.5 & $5.39 \times 10^{-9}$ & 0.44 & 3990 & 42457 \\
4.3 & $6.11 \times 10^{-9}$ & 0.37 & 4703 & 53535 \\
5.3 & $3.22 \times 10^{-9}$ & 0.50 & 5454 & 68566 \\
\hline 6.5 & $3.65 \times 10^{-9}$ & 0.44 & 7004 & 69446 \\
\hline 9
\end{tabular}



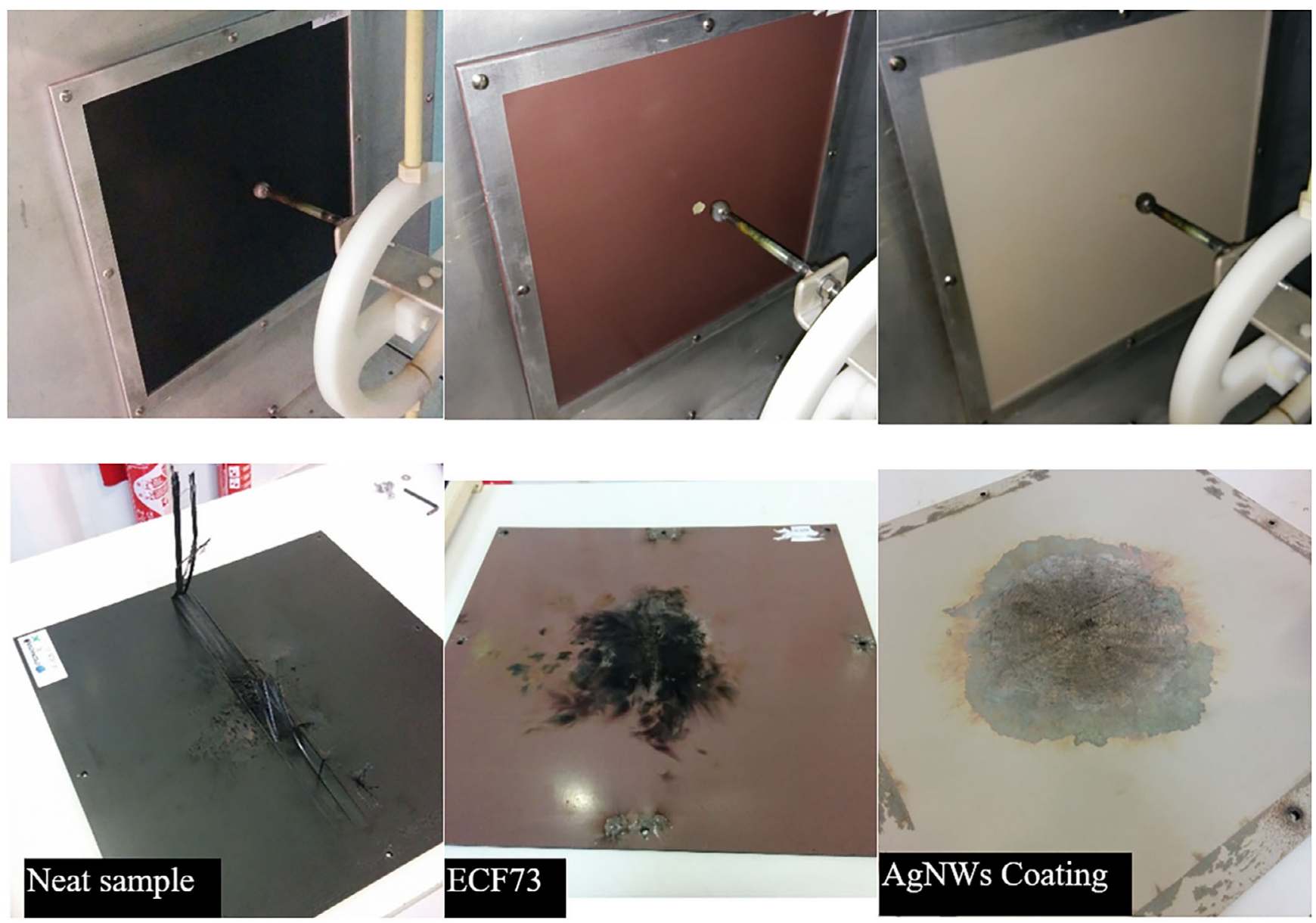

Figure 9. Nonimpacted (top) and impacted (bottom) samples without LSP (right), with ECF73 (center) and with AgSWs coating 8\% in volume. [Color figure can be viewed at wileyonlinelibrary.com]

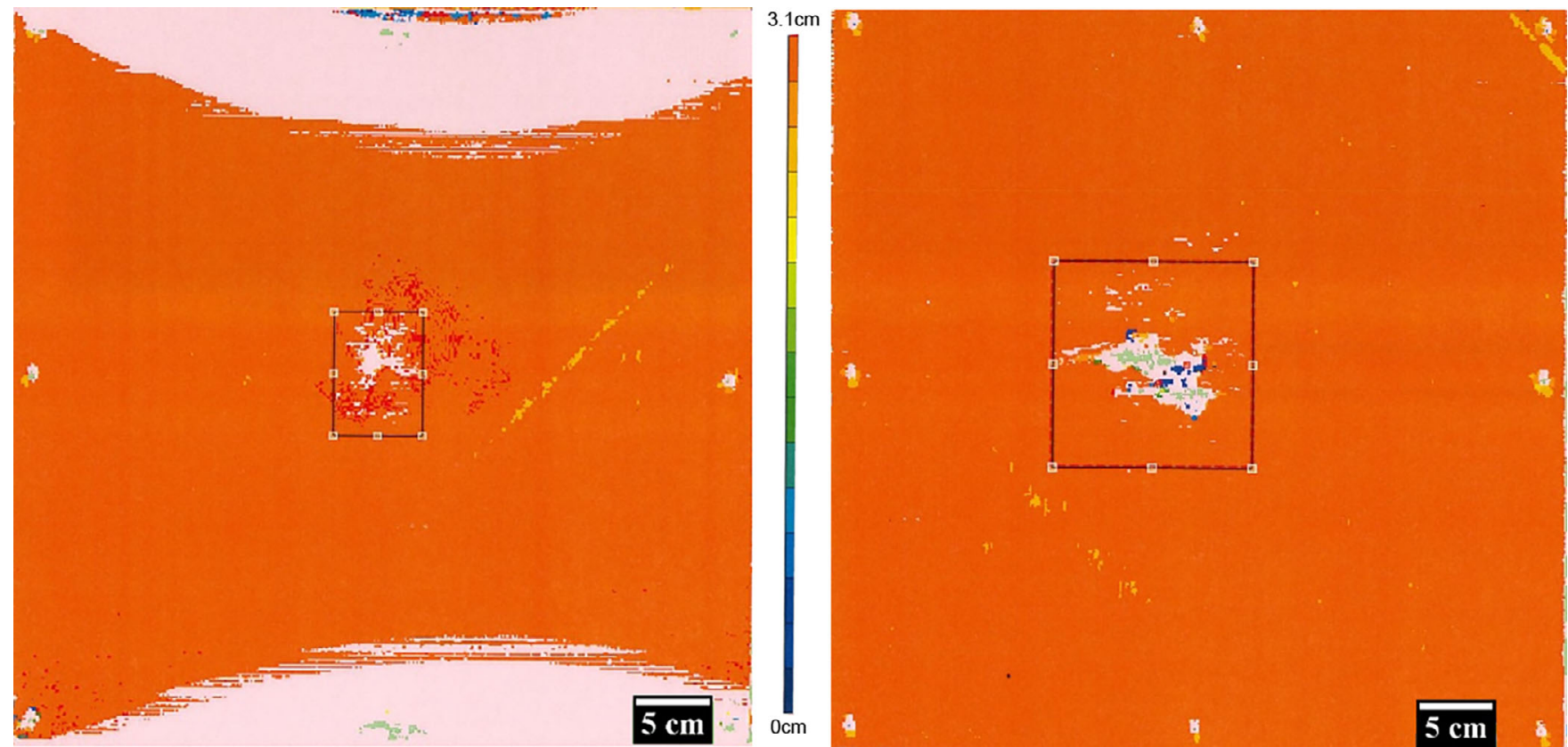

Figure 10. On the left, C-scan mapping of a CFRP protected by ECF73 and on the right, AgSWs coating. [Color figure can be viewed at wileyonlinelibrary.com] 
Ultrasonic Testing. The ultrasonic testing technic was used to point out structural defaults such as delamination induced by the lightning strike in the volume. This type of defect must be avoided in order to maintain the aeronautical requirements. The damage area is confined in the layer containing the lightning protection. The defects' depth and area were measured on both configuration samples (Figure 10).

No structural degradation due to a delamination was observed. We note a slight curvature in the case of ECF probably due to the thermal expansion coefficient difference between the CFRP and the ECF (light areas at the top and the bottom of the mapping on Figure 10 left side). The ECF LSP and AgSWs coating exhibit a comparable level of protection against the lightning strike. In both cases, the CFRP has been protected against the delamination. The ultrasonic measurement confirms, as the visual inspection, the efficiency of the two configurations with the LSP.

\section{CONCLUSION}

The elaboration of a new kind of low-filled conductive coating was developed for LSP. The influence of AgSWs on electrical behaviors of a poly(epoxy) coating system has been determined. The SEM observations have shown a homogenous dispersion with a slight orientation due to the air spray processing and the maintenance of the high aspect ratio of the AgSWs' $(\xi \approx 200)$. The $J(E)$ behaviors of conductive composite poly(epoxy)/AgSWs were studied. $J(E)$ is linear for a large voltage or intensity scale. The experimental measurements were compared to the conduction mechanism of several systems. The conductive coatings exhibit a temperature behavior close to the metal. The Ohmic mechanism is preponderant. The highest value of the electrical conductivity was measured around $5.5 \times 10^{5} \mathrm{~S} \mathrm{~m}^{1}$ (9\%vol of AgSWs for the isotherm $-60^{\circ} \mathrm{C}$ ). It is one of the highest values for coating with low content conductive filler. However, this value is 100 times lower than the bulk silver conductivity. The limit electric field experiments showed that the current is meanly limited by the AgSWs melting. The conductive coating acts as an electric parallel circuit where the current is divided by the wires number. This heterogeneous material exhibits a nonconventional behavior; the electrical conductivity level is not enough to dissipate the energy amount. The hopping and tunneling complementary conductive mechanisms between wires were driven by a barrier energy gap to cross. These mechanisms imply an energy consumption proportional to the wires number. An important level of current density dissipation is performed by adjusting the wires number (filler content) and the cross section (thickness of conductive coating). A specific configuration (conductive coating filled with $8 \%$ vol of AgSWs) was applied on a CFRP aeronautical structure. A lightning strike test was performed and compared with a classical ECF protection for aeronautical structures. CFRP covered with the conductive epoxy/AgSWs exhibits a comparable level of protection with a lower impact on the structure weight (56\%). The proposed solution is efficient and could be a realistic solution for the LSP aeronautic structures requirements.

\section{ACKNOWLEDGMENTS}

These results were obtained under the research project "COMPINNOVTD" at the IRT Saint Exupéry. We thank the industrial and academic members of the IRT who supported this project through their contributions, both financial and in terms of specific knowledge:

- Industrial members: Airbus Operations, ArianeGroup, Airbus Helicopters, Airbus Group Innovations, STELIA Aerospace, and Thales Alenia Space

- Academic members: CIRIMAT, UPS, and CNRS

We also thank the Commissariat Général aux Investissements and the Agence Nationale de la Recherche for their financial support in the Programme d'Investissement d'Avenir (PIA).

\section{REFERENCES}

1. Lonjon, A.; Demont, P.; Dantras, E.; Lacabanne, C. J. Non Cryst. Solids. 2012, 358, 1859.

2. Wang, S.; Chung, D. D. L. Compos. Interfaces. 1998, 6, 497.

3. Chemartin, L.; Lalande, P.; Peyrou, B.; Chazottes, A.; Elias, P. Q.; Delalondre, C.; Cheron, B. G.; Lago, F. AerospaceLab. 2012, 1.

4. Li, Y.; Li, R.; Lu, L.; Huang, X. Compos. Part A Appl. Sci. Manuf. 2015, 79, 164.

5. Wang, Y. Compos. Part A Appl. Sci. Manuf. 2017, 101, 543.

6. Plumer, J.; Robb, J. IEEE Trans. Electromagn. Compat. 1982, EMC-24, 158.

7. Gagné, M.; Therriault, D. Prog. Aerosp. Sci. 2014, 64, 1.

8. Kawakami, H.; Feraboli, P. Compos. Part A Appl. Sci. Manuf. 2011, 42, 1247.

9. Fisher, F. A.; Plumer, J. A. Lightning Protection of Aircraft; NASA Scientific and Technical Information Office, 1977.

10. Katnam, K. B.; Da Silva, L. F. M.; Young, T. M. Prog. Aerosp. Sci. 2013, 61, 26.

11. Medalia, A. I. Rubber Chem. Technol. 1986, 59, 432.

12. Psarras, G. C. J. Polym. Sci. Part B Polym. Phys. 2007, 45, 2535.

13. Barrau, S.; Demont, P.; Peigney, A.; Laurent, C.; Lacabanne, C. Macromolecules. 2003, 36, 5187.

14. Bauhofer, W.; Kovacs, J. Z. Compos. Sci. Technol. 2009, 69, 1486.

15. Han, J.; Zhang, H.; Chen, M.; Wang, D.; Liu, Q.; Wu, Q.; Zhang, Z. Carbon N. Y. 2015, 94, 101.

16. Gou, J.; Tang, Y.; Liang, F.; Zhao, Z.; Firsich, D.; Fielding, J. Compos. Part B Eng. 2010, 41, 192.

17. Liao, K.-H.; Qian, Y.; Macosko, C. W. Polymer (Guildf). 2012, 53, 3756.

18. Shevchenko, V. G.; Polschikov, S. V.; Nedorezova, P. M.; Klyamkina, A. N.; Shchegolikhin, A. N.; Aladyshev, A. M.; Muradyan, V. E. Polymer (Guildf). 2012, 53, 5330.

19. Balberg, I.; Anderson, C. H.; Alexander, S.; Wagner, N. Phys. Rev. B. 1984, 30, 3933.

20. Kirkpatrick, S. Rev. Mod. Phys. 1973, 45, 574.

21. Bauhofer, W.; Schulz, S. C.; Eken, A. E.; Skipa, T.; Lellinger, D.; Alig, I.; Tozzi, E. J.; Klingenberg, D. J. Polymer (Guildf). 2010, 51, 5024. 
22. Gurland, J. Trans. Metall. Soc. aime. 1966, 236, 642.

23. Untereker, D.; Lyu, S.; Schley, J.; Martinez, G.; Lohstreter, L. ACS Appl. Mater. Interfaces. 2009, 1, 97.

24. Lonjon, A.; Laffont, L.; Demont, P.; Dantras, E.; Lacabanne, C. J. Phys. Chem. C. 2009, 113, 12002.

25. Audoit, J.; Laffont, L.; Lonjon, A.; Dantras, E.; Lacabanne, C. Polymer (Guildf). 2015, 78, 104.

26. Nguyen, T. H. L.; Quiroga Cortes, L.; Lonjon, A.; Dantras, E.; Lacabanne, C. J. Non Cryst. Solids. 2014, 385, 34.

27. Ramachandran, L.; Lonjon, A.; Demont, P.; Dantras, E.; Lacabanne, C. Mater. Res. Express. 2016, 3, 085027.

28. Stejskal, J. Chem. Pap. 2013, 67, 814.

29. Kim, J. M.; Jang, K.; Lee, S. J. J. Appl. Polym. Sci. 2019, 136, 47927.

30. Lonjon, A.; Dantas, E.; Demont, P.; Lacabanne, C. Pat. WO/2010/012935 (2010).

31. Bedel, V.; Lonjon, A.; Dantras, É.; Bouquet, M. J. Appl. Polym. Sci. 2018, 135, 46829.

32. Lonjon, A.; Demont, P.; Dantras, E.; Lacabanne, C. J. Non Cryst. Solids. 2012, 358, 236.

33. Lonjon, A.; Caffrey, I.; Carponcin, D.; Dantras, E.; Lacabanne, C. J. Non Cryst. Solids. 2013, 376, 199.

34. Cortes, L. Q.; Lonjon, A.; Dantras, E.; Lacabanne, C. J. Non Cryst. Solids. 2014, 391, 106.

35. Wiley, B.; Sun, Y.; Xia, Y. Langmuir. 2005, 21, 8077.

36. Sun, Y. Adv. Mater. 2002, 14, 833.

37. Sun, Y.; Yin, Y.; Mayers, B. T.; Herricks, T.; Xia, Y. Chem. Mater. 2002, 14, 4736.

38. Coleman, J.; Curran, S.; Dalton, A.; Davey, A.; McCarthy, B.; Blau, W.; Barklie, R. Phys. Rev. B - Condens. Matter Mater. Phys. 1998, 58, R7492.

39. Narkis, M.; Ram, A.; Flashner, F. Polym. Eng. Sci. 1978, 18,649 .
40. Mott, N. F. Adv. Phys. 1967, 16, 49.

41. Mott, N. F.; Davis, E. A. Electronic Processes in NonCrystalline Materials 2nd ed.; Clarendon Press: Oxford, 1979.

42. Efros, A. L.; Phys, J. C Solid State Phys. 1976, 2021, 9.

43. Schwarz, R. J. Non Cryst. Solids. 1998, 148, 227.

44. Teyssedre, G.; Laurent, C. IEEE Trans. Dielectr. Electr. Insul. 2005, 12, 857.

45. Baranovski, S. Charge Transport in Disordered Solids with Applications in Electronics; Philipps University Marburg: Germany, 2006.

46. Blaise, G. J. Electrostat. 2001, 50, 69.

47. Dissado, L. A.; Fothergill, J. C. In Electrical Degradation and Breakdown in Polymers; Stevens, G. C., Ed., P. Peregrinus Ltd.: United Kingdom, 1992.

48. Child, C. D. Phys. Rev. (Series I). 1911, 32, 492

49. Stallinga, P. Electrical Characterization of Organic Electronic Materials and Devices; John Wiley \& Sons: Chichester, UK, 2009.

50. Ramamurthy, P. C.; Malshe, A. M.; Harrell, W. R.; Grego, R. V.; McGuire, K.; Rao, A. M. International Semiconductor Device Research Symposium; IEEE: Washington, DC, USA, 2003; p. 208.

51. Sheng, P.; Sichel, E. K.; Gittleman, J. I. Phys. Rev. Lett. 1978, 40, 1197.

52. Jović, N.; Dudić, D.; Montone, A.; Antisari, M. V.; Mitrić, M.; Djoković, V. Scr. Mater. 2008, 58, 846.

53. Upadhyay, D. C.; Goyal, E. M.; Goel, J. P. Physics: E-Book. 1st ed; SBPD Publications: Meerut, India, 2016.

54. Eccles, W. H. Proc. Phys. Soc. London. 1909, 22, 289.

55. Sondheimer, E. H. Adv. Phys. 1952, $1,1$.

56. Preece, W. H. Proc. R. Soc. London. 1883, 36, 464.

57. Stauffacher, E. R. Gen. Electr. Rev. 1928, 31, 326. 